\title{
Virtualização de Jogos Matemáticos: uma Avaliação do Cubra Doze
}

\author{
Ana Carolina Santos Silva, Taciana Pontual Falcão \\ Departamento de Computação - Universidade Federal Rural de Pernambuco (UFRPE) - \\ Recife - PE - Brasil \\ a.caroolinasantosegmail.com, taciana.pontual@ufrpe.br
}

\begin{abstract}
The present research is guided by the growing use of games in education, as a teaching methodology that joins fun, logical reasoning, strategic planning, among other aspects. With the increasing ubiquity of technological devices in people's daily lives, using digital technology in education is an inevitable trend. The aim of this research is to analyze the contributions of the digital version of an educational game about basic Mathematical operations, aiming at bringing together the positive results of traditional games in teaching and the growing demand and interest of children and young people for digital games. To do this, the game Cubra Doze was transformed into a digital version and conducted a study with students of the 1st year of high school to gauge the motivation and aspects of HumanComputer Interaction with the game. The results revealed that there were positive results both in terms of engaging in learning using a digital game and in the collaboration and educational content attached to it, thus demonstrating that games are good educational tools.
\end{abstract}

Resumo. A presente pesquisa é norteada pelo uso crescente de jogos na educação, como uma metodologia de ensino que une diversão, raciocínio lógico, planejamento estratégico, entre outros aspectos. Com a crescente ubiquidade de dispositivos tecnológicos no cotidiano das pessoas, utilizar-se da tecnologia digital na educação é uma tendência inevitável. Visando aproximar os resultados positivos dos jogos tradicionais no ensino, e a crescente demanda e interesse de crianças e jovens por jogos digitais, o objetivo dessa pesquisa é analisar as contribuições da versão digital de um jogo educacional sobre as operações básicas de Matemática. Para isso, foi transformado o jogo Cubra Doze em uma versão digital e conduzido um estudo com estudantes do $1^{\circ}$ ano do Ensino Médio para aferir a motivação e aspectos de Interação Humano-Computador com o jogo. Os resultados revelaram que houve resultados positivos tanto em relação ao engajamento em aprender utilizando um jogo digital como na colaboração e conteúdo educacional atrelado a ele, demonstrando assim que jogos são boas ferramentas educacionais. 


\section{Introdução}

A evolução das tecnologias digitais no âmbito escolar traz uma nova visão ao modelo de ensino-aprendizagem tradicionalmente utilizado em sala de aula. Cada vez mais, essas tecnologias estão inseridas na escola e no processo de aprendizagem do aluno, seja através de equipamentos digitais ou projetos que a envolvam. $\mathrm{O}$ uso crescente de jogos digitais na educação, como uma metodologia de ensino lúdica que une diversão, raciocínio lógico, planejamento estratégico e pensamento computacional, vem gerando cada vez mais reflexões quanto ao papel da escola em relação a essa evolução.

Entretanto, jogos educacionais sem aspectos digitais, comumente utilizados com resultados positivos no ensino, têm sido substituídos por jogos digitais que muitas vezes não possuem base psicopedagógica e que têm a função lúdica se sobrepondo ao contexto pedagógico [Felicia, 2009]. Visando maximizar os benefícios que os jogos digitais têm no ensino-aprendizagem é possível encontrar na literatura alguns autores, como dos Santos et al. [2015] abordando o que chamam de "virtualização de jogos tradicionais", que é uma técnica que une os princípios pedagógicos consolidados nos jogos tradicionais às novas plataformas digitais, dando suporte aos professores para que trabalhem de forma lúdica, mas com conteúdos pré estabelecidos [Santos et al., 2013].

Todos esses dados nos levam a considerar três aspectos importantes sobre a eficácia de jogos no âmbito escolar: o conteúdo pedagógico atrelado a eles, a ludicidade, e o engajamento que geram nos alunos. Isto leva ao objetivo geral da presente pesquisa, que pretende analisar as contribuições da versão digital do jogo educacional Cubra Doze, no contexto de aprendizagem das operações básicas de Matemática. A fim de alcançar o objetivo, foi desenvolvida uma versão digital do jogo escolhido, a qual foi aplicada em uma turma de $1^{\circ}$ ano de uma escola estadual. Por meio de observação do uso do jogo e questionários passados aos alunos, pôde-se analisar aspectos pedagógicos, de interação e engajamento.

O que se espera com este trabalho é incentivar mais profissionais a trabalhar com a abordagem de adaptação de jogos tradicionalmente utilizados na educação a um formato digital, visando aproveitar as suas contribuições para a aprendizagem e proporcionar experiências mais motivadoras aos alunos. $\mathrm{O}$ artigo está estruturado da seguinte forma: na seção 2, apresentamos uma visão geral sobre uso de jogos digitais para aprendizagem de matemática. Na seção 3, descrevemos a metodologia adotada para o experimento e avaliação do jogo proposto. Na seção 4, apresentamos os resultados obtidos, e uma discussão acerca do engajamento dos estudantes com o jogo, e aspectos relacionados à usabilidade da interface. As conclusões são apresentadas na seção 5 .

\section{Jogos digitais na educação Matemática}

A crescente demanda de desenvolvimento de jogos digitais tem despertado interesse entre pesquisadores de tecnologias voltadas à educação. Há evidências de que os jogos podem ajudar no desenvolvimento cognitivo e propiciar um conhecimento mais sólido do que os conteúdos adquiridos através do modelo tradicional de ensino por transmissão de conhecimento [Brom et al., 2011].

Levando em consideração que essas tecnologias expandem as possibilidades de aprender e ensinar, vários pesquisadores confirmam essa teoria em relação a educação matemática, como: da Silva Neto et al. [2013], que defendem o uso de jogos digitais 
como um meio motivacional no processo de aprendizagem, principalmente em matérias com um índice maior de rejeição, sendo apontado por eles as disciplinas de Matemática e Física; Kafai [1995] e Rosa [2004] com a construção de jogos digitais para trabalhar conteúdos matemáticos como frações e números inteiros, enfatizando assim o potencial de se utilizar jogos digitais para trabalhar conteúdos educacionais.

Santos e da Silva Junior [2014] afirmam que com o passar dos anos, os jogos tradicionais utilizados para ensino de Matemática foram entrando em desuso na mesma medida em que pesquisas e jogos digitais educacionais foram sendo projetados. Pela disparidade encontrada pelos autores entre os jogos tradicionais e os jogos digitais, quanto ao seu conteúdo pedagógico, eles defendem a necessidade de resgatar jogos anteriormente usados no formato físico, agora na forma digital.

Essa ideia da virtualização de jogos tradicionais também se baseia no fato de que estudos como da Silva e Costa [2017] e Batista et al. [2017] têm tido resultados consideráveis do uso de jogos digitais como o aumento da motivação dos alunos em participar de aulas que utilizem jogos digitais como ferramenta de apoio à aprendizagem, da mesma forma há pesquisas como a de de Oliveira [2014] e Ribeiro Junior [2018] que demonstram que os jogos tradicionais ainda possuem uma contribuição para o pensamento lógico. Sendo assim, para que não se percam os benefícios do jogo físico, propõe-se essa transformação, pois conforme pode ser visto em de Santana e dos Santos [2018], através da comparação da aplicação de um jogo em sua forma tradicional (sem aparatos digitais) e sua forma digital, fica claro que há um maior engajamento por parte dos estudantes de hoje quando o jogo encontra-se em formato digital.

\section{Metodologia}

Com o objetivo de analisar as contribuições da versão digital de um jogo educacional sobre as operações básicas de Matemática, foi desenvolvida uma versão digital do jogo Cubra Doze, que foi então avaliada com estudantes, conforme a metodologia descrita a seguir.

\subsection{Transformação do jogo Cubra Doze para formato digital}

A transformação de um jogo tradicional (físico) para sua versão digital, que dos Santos [2018] chama de "virtualização", consiste em preservar os conceitos educacionais do jogo e combiná-los com elementos de design de interação, a fim de aumentar o engajamento por parte dos jovens e favorecer a aprendizagem. O jogo Cubra Doze foi escolhido após um levantamento bibliográfico de jogos matemáticos de tabuleiro existentes e que ainda não possuíam uma versão digital, e devido à possibilidade de trabalhar com questões primordiais para alunos tanto do Ensino Fundamental quanto do Ensino Médio, como: conteúdos matemáticos envolvendo as quatro operações aritméticas, cálculo mental, atenção, agilidade de raciocínio, além de desenvolvimento cognitivo, afetivo e emocional. Em entrevista informal com o professor de Matemática parceiro da pesquisa, foi possível constatar que a sua turma de 1o ano do Ensino Médio possui dificuldades em trabalhar os conteúdos mais elaborados e indicados para seu ano letivo, por conta de deficiências no conhecimento básico.

O jogo original consiste em um tabuleiro com enumerações de um a doze em suas laterais, além de dois dados e vinte e quatro marcadores. Ao lançar os dados, é 
necessário realizar operações matemáticas com os números sorteados, e marcar o resultado em um dos doze números do tabuleiro. Vence o jogador que preencher primeiro todos os números do seu lado do tabuleiro. Visando aumentar o grau de dificuldade do jogo e a possibilidade de se trabalhar com o conteúdo de ordem das operações, foi adicionado na versão digital mais um dado (totalizando três), fazendo com que as operações tenham que ser feitas com os três números que forem sorteados, e respeitando a regra de ordem das operações (desconsiderando a existência de parênteses), ou seja: as operações de multiplicação e divisão não podiam ser feitas antes das operações de soma e subtração. Um temporizador de 60 segundos, com efeito sonoro, também foi adicionado a cada rodada. A validação das ações dos jogadores é feita pelo jogo e exibida na tela de acordo com os seguintes casos: o jogador errou o resultado da operação (o jogo informa o resultado correto); o jogador errou a ordem das operações (o jogo indica que é necessário realizar as operações na ordem correta); o jogador tentou preencher um campo do tabuleiro que já estava preenchido (o jogo notifica); e o jogador acertou a operação (nesse caso o campo correspondente ao resultado é preenchido).

O jogo digital foi dividido em:

- Tela de introdução: onde é possível visualizar a explicação do objetivo e regras do jogo, através de um avatar, além de conter um componente sonoro de inicialização de jogo.

- Tela de criação de partida: onde criam-se nomes para as equipes, e de forma randômica o jogo decidirá quem vai iniciar com a vez de jogo.

- Tela de início de partida: apresenta os 24 campos do tabuleiro, separados de 1 a 12 em dois lados, bem como a informação de qual equipe iniciará a partida e o botão de "sortear números" (Figura 1).

- Tela de resposta: onde são exibidos os três números gerados randomicamente, e há componentes de interface para que o jogador selecione os números e os operadores (montando a operação que deseja efetuar). Para esse preenchimento, o usuário utiliza um componente de escolha1 que disponibiliza as opções possíveis (ou seja, os números sorteados, ou as operações matemáticas). Já para o preenchimento do resultado da operação, é utilizado um componente para preenchimento manual do valor2 através do teclado. Nesta tela é possível "Pular a vez" ou "Responder" e há um temporizador visual (no canto superior esquerdo), complementado com um som de "tique taque" de relógio, indicando o tempo restante para montar a operação (Figura 2).

- Tela de vitória: a equipe ou o jogador que completar os doze campos primeiro vence o jogo, e é exibida uma tela de vitória com um efeito sonoro e a opção de "Jogar novamente" ou "Sair".

\footnotetext{
1 Este componente permite disponibilizar uma ou mais opções em um menu para que o usuário selecione o elemento desejado.

2 Componente utilizado para receber dados do usuário.
} 


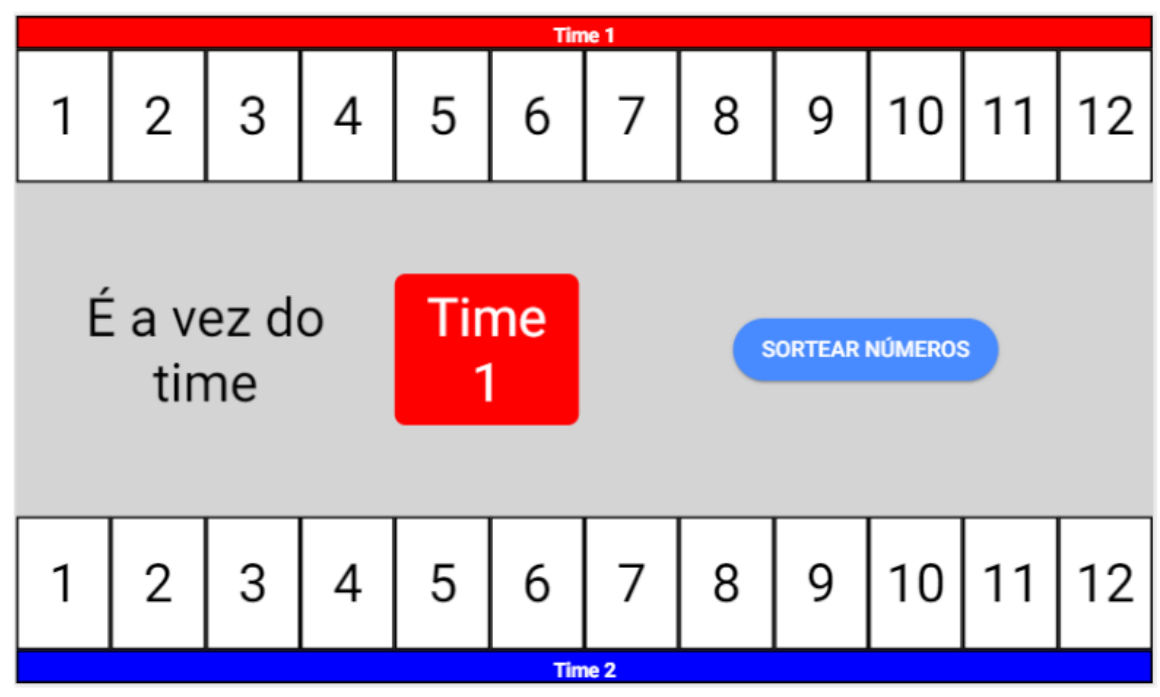

Figura 1. Tela de Início

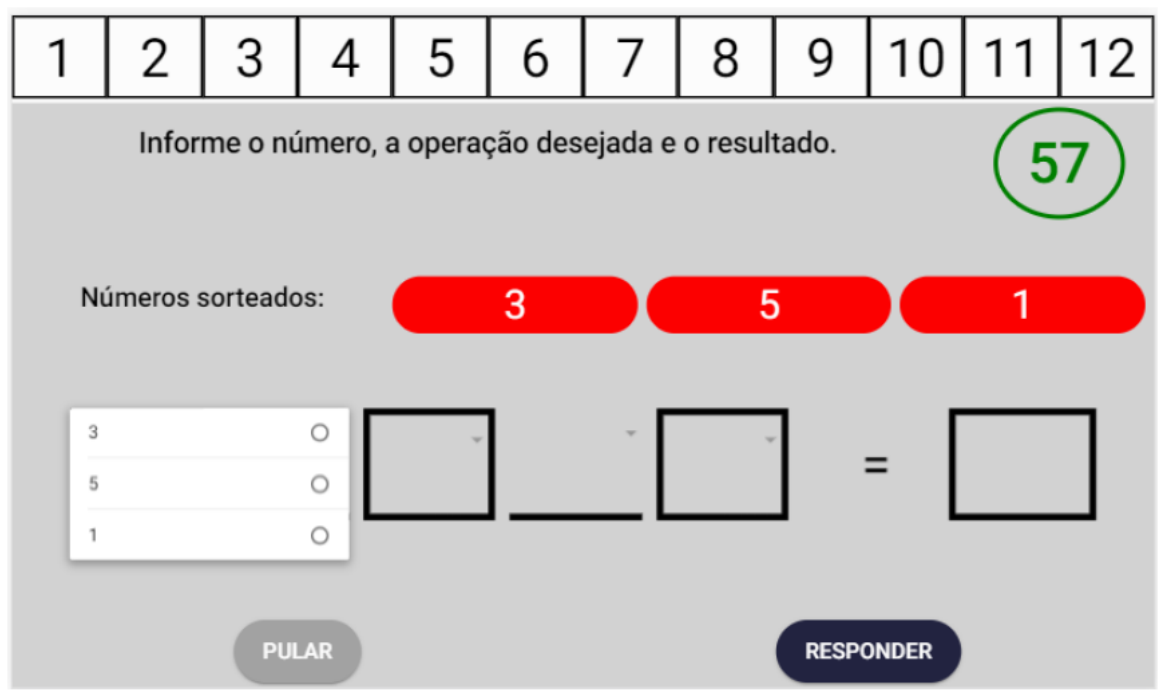

Figura 2. Tela de Resposta

O jogo inicialmente foi projetado para dispositivos móveis, no entanto precisou ser adaptado para execução via navegador web, para utilização dos computadores do tipo netbook, disponibilizados pela escola participante. Antes da aplicação foram realizados a configuração e testes do jogo em todos os netbooks disponibilizados de forma individual visando validar o seu funcionamento e a conexão com a internet.

\subsection{Aplicação do Jogo}

Os participantes da pesquisa foram alunos do $1^{\circ}$ ano do Ensino Médio de uma escola técnica estadual. Ao todo participaram 32 (trinta e dois) alunos, sendo 13 participantes do sexo feminino e 19 participantes do sexo masculino, com idades variando entre 14 (quatorze) e 17 (dezessete) anos. O professor de Matemática da turma participou do experimento auxiliando na concepção, aplicação e observação da pesquisa. $O$ estudo ocorreu em dois encontros, dando um total de 3 horas e 30 minutos.

No primeiro encontro com a turma, foram apresentados o contexto do trabalho e o objetivo da pesquisa, e foi explicado aos alunos quais conteúdos matemáticos eram 
possíveis de serem trabalhados com a utilização do jogo Cubra Doze. Para um maior esclarecimento, o jogo foi demonstrado em seu formato físico de tabuleiro, que foi jogado com o professor da turma para que os alunos compreendessem as regras e objetivo. Após essa breve demonstração a turma foi dividida em grupos, postos a jogar entre si a versão digital, nos netbooks. Não foi dada nenhuma instrução aos participantes sobre o funcionamento do jogo no dispositivo, com o intuito de analisar aspectos de Interação Humano-Computador relacionados a usabilidade. Neste primeiro dia, a turma foi dividida em 12 equipes, sendo 10 delas compostas por 3 alunos cada, 1 composta por 2 alunos e 1 composta por 1 aluno. Os alunos também responderam a um questionário semiestruturado composto por perguntas abertas e fechadas com o intuito de identificar seu perfil, com questões como idade, sexo, aptidão em Matemática e opinião quanto ao uso de materiais extras em sala de aula. O foco da primeira aplicação do jogo foi na observação do desempenho e interação dos alunos com o jogo, anotando as observações em um diário de campo. Para esta primeira etapa teve-se a participação 5 voluntários para o registro de dados: a pesquisadora, a professora orientadora da pesquisa, o professor de Matemática, e duas monitoras da turma. Todos realizaram observações e anotações acerca do feedback dos alunos, problemas de interação com o jogo e melhorias sugeridas pelos alunos participantes.

No segundo encontro, a turma tornou a ser dividida e foi criado um campeonato onde as equipes jogavam entre si, através de chaveamentos, até chegar numa equipe vencedora. A mediação e observações de campo foram realizadas pela pesquisadora, professora orientadora, e professor de Matemática. Após aplicação do jogo, foi distribuído para os alunos da turma um questionário baseado no modelo de avaliação de jogos educacionais proposto por Savi et al. [2010], que é direcionado a jogos com objetivos educacionais bem definidos e que sirvam de material de ensino para professores. O questionário proposto pretende avaliar se o jogo (i) consegue motivar os estudantes a utilizarem o recurso como material de aprendizagem; (ii) proporciona uma boa experiência aos usuários; e (iii) gera uma percepção de utilidade educacional entre seus usuários (ou seja, se os alunos acham que estão aprendendo com o jogo) (Savi et al. (2010), p.2).

\section{Resultados e Discussões}

Pudemos verificar com as informações obtidas através do questionário inicial aplicado, que apenas $6 \%$ dos participantes estão fora da faixa etária adequada para alunos do $1^{\mathrm{o}}$ ano do Ensino Médio, além de identificar que boa parte da turma (72,7\%) tem dificuldades com a disciplina de Matemática, mesmo mais da metade da turma $(66,7 \%)$ informando que gosta ou acha interessante a disciplina. Foi possível notar também que mais da metade da turma $(57,6 \%)$ já fez uso de materiais de apoio lúdicos como jogos e videoaulas, para complementar seu aprendizado.

\subsection{Análise de Aspectos de Interação Humano-Computador}

Com base nas observações qualitativas registradas em diário de campo, percebe-se que os estudantes conseguiram interagir bem com o jogo, visto que não houve dificuldades impeditivas em termos de design de interação para concluir o jogo. Entretanto, alguns aspectos de melhoria foram identificados. 
Foi verificado quanto à questão de usabilidade do jogo que os participantes tentavam inicialmente (e repetidas vezes) tocar com a caneta touch nos números sorteados e arrastá-los para os campos de entrada das operações, ficando surpresos diante da impossibilidade de executar a ação. Boa parte das equipes demonstrou dificuldade em entender como deveriam ser preenchidos os números sorteados e as operações a serem realizadas na tela de Resposta, mas após algumas repetições neste formato de utilização (selecionando dentre as opções, por meio do pequeno menu no próprio componente de entrada), os participantes começaram a interagir mais rápido. Ainda assim, percebeu-se que a forma de interação ideal para o público-alvo seria por tocar e arrastar os elementos.

Outro problema identificado foi em relação à posição dos números no tabuleiro virtual. Na tela inicial, cada time possui uma cor específica e uma posição na tela (Time 1 na borda superior e Time 2 na borda inferior), conforme pode ser visto na Figura 1, com os respectivos campos de números de 1 a 12. No entanto, na tela de resposta, a disposição da interface muda, e o conjunto de números fica sempre na borda superior, independentemente do time. Embora a tela de resposta tenha sido pensada da forma mais conveniente para o time que está na vez, a alternância da disposição dos elementos na tela quebra o princípio de consistência e gerou certa confusão para os usuários sobre de quem era a vez realmente (Figura 2).

Por fim, a inclusão do tempo de resposta para cada equipe funcionou especialmente bem como um fator motivacional, e a sonorização em algumas etapas do jogo foi vista como agradável, tendo uma observação por parte de um participante que relatou que "a música deveria estar presente durante todo o jogo".

\subsection{Análise do Engajamento}

Com base nas observações qualitativas registradas em diário de campo, de forma geral a turma aparentou um grande engajamento, conforme os seguintes indícios. Após a primeira rodada do primeiro encontro, todos quiseram jogar novamente e todos optaram por manter os grupos e desafiar as mesmas equipes como uma "revanche". Na segunda rodada do jogo foi notório que os alunos estavam mais concentrados e já haviam escolhido uma estratégia para seguir, refletindo também nos momentos de efusão (alguns gritos, palmas e risos) que diminuíram. No segundo encontro, houve grupos que foram eliminados da competição, mas quiseram continuar jogando entre si, mesmo não fazendo mais parte da competição geral. Nenhum estudante se recusou a jogar ou quis abandonar as partidas.

Pudemos observar que o formato de tela do netbook na vertical gerava certa distração por parte da equipe que não estava com a vez, já que a tela estava virada para a equipe adversária e não tinha como acompanhar de forma fácil a vez do outro time. Esse formato da tela também gerou certa desconfiança na ação do time adversário e foi possível perceber também, em alguns grupos, que enquanto estava na vez do time oponente, o time que aguardava ficava tentando distraí-los para que perdessem a vez devido a tempo esgotado.

Ao chegar perto do fim da execução das atividades, pôde-se notar que alguns participantes se distraíam em conversas ou com o uso de celular, pois como a equipe foi formada por 3 integrantes, acabou predominando um jogador como "líder", na maioria dos casos. Ainda assim, praticamente todos os integrantes do grupo interagiam durante a 
atividade e opinavam quanto à melhor estratégia para se preencher os valores. Foi possível identificar que houve uma colaboração positiva por parte das equipes, onde os grupos discutiam possíveis soluções e estratégias para conseguir marcar mais um resultado. Houve casos em que os participantes pensavam em operações em ordens diferentes mas que davam o mesmo resultado e durante discussão acabaram perdendo a vez devido ao tempo.

Foi possível perceber que boa parte das equipes utilizava predominantemente a operação de soma, e somente perto do fim do jogo, quando as opções de campos para se preencher haviam diminuído, utilizavam mais as outras operações. Na segunda rodada, quando os participantes estavam familiarizados com o jogo, foi possível perceber que tentavam preencher os números "mais difíceis" de serem encontrados, então começaram a utilizar de estratégias com o uso de todas as operações. Constatamos que os alunos erraram poucas vezes os resultados das operações e não tiveram dificuldade em seguir a regra da ordem das operações. No entanto, a predominância do uso da soma foi um ponto a ser estudado no sentido de achar uma forma de estimular os estudantes a buscarem outras soluções, para que assim exercitem mais o raciocínio matemático.

\subsection{Análise do Questionário de Avaliação de Jogos Educacionais}

À medida em que os participantes finalizavam as atividades do jogo, foi distribuído um questionário de afirmações, para indicarem se concordam ou não, baseado no modelo de avaliação de jogos educacionais proposto por Savi et al. (2010) e que pretende avaliar se o jogo consegue motivar os estudantes a utilizá-lo como material de apoio ao ensino, se os estudantes sentem que estão aprendendo com ele e se proporciona uma experiência válida.

Os resultados obtidos com a aplicação do questionário permitiram perceber que o design simples e direto fez com que o entendimento do jogo fosse satisfatório, bem como a clareza dos objetivos educacionais ligados a ele. $\mathrm{O}$ entendimento por parte dos jogadores quanto ao conteúdo educacional ligado ao jogo foi um fator que motivou os alunos, que pode ser visto na afirmação "O conteúdo do jogo será útil para mim" onde 93,8\% concordaram além de $96,9 \%$ afirmarem que o conteúdo do jogo está relacionado com coisas que já sabia". Podemos destacar também que $87,1 \%$ dos participantes afirmaram que o jogo permite contribuições para compreensão dos assuntos matemáticos atrelados, além de afirmarem ser uma ferramenta motivadora e que gera satisfação ao conseguir atingir seus objetivos.

Percebeu-se ainda a partir das respostas do questionário que $90 \%$ dos participantes gostou do jogo e o $93,8 \%$ o utilizaria novamente. Mesmo que 90,3\% dos alunos afirmarem que se sentiram estimulados a aprender com o jogo, pudemos constatar que devido ao jogo ser bastante objetivo e não possuir novos desafios, como níveis de dificuldade, não seria uma ferramenta com um bom aproveitamento a longo prazo para motivação do aprendizado. Isto pode ser visto através do resultado da afirmação "Eu gosto de utilizar este jogo por bastante tempo", da qual 56,3\% dos participantes discordaram.

Ainda referente a experiência do usuário, tivemos como resultado que $90 \%$ dos alunos se sentiram estimulados a aprender com o jogo e se sentiram bem-sucedidos no decorrer do desafio. O sentimento de colaboração também é um ponto a ser destacado, 
pois $96,9 \%$ dos participantes concordaram com as afirmações "senti que estava colaborando com outros colegas" e "a colaboração no jogo ajuda a aprendizagem".

Em relação ao sentimento de aquisição de conhecimento, 90,3\% dos participantes concordaram com a afirmação "Depois do jogo sinto que consigo aplicar melhor os temas relacionados com o jogo", o que evidencia o benefício de se utilizar de objetos digitais para apoio da aprendizagem.

Apesar de ser um jogo inicialmente projetado para dois jogadores, percebe-se que foi possível e proveitoso, do ponto de vista de engajamento e aprendizagem colaborativa, propor as partidas em equipes. Esses resultados confirmam as observações realizadas pelos pesquisadores, quando destacam a interação nos momentos em que era necessário elaborar uma expressão matemática mais complicada que conseguisse como resultado o valor a ser preenchido. Apesar dessa interação não ocorrer durante todo o momento do jogo, todas as observações apontaram que havia um diálogo no grupo para planejamento da operação ou explicação da expressão proposta.

\section{Conclusão}

A utilização de jogos digitais voltados à educação tem sido, cada vez mais, alvo de pesquisa enquanto ferramenta para auxílio do processo de ensino-aprendizagem. Dessa forma, e com todos os benefícios encontrados por experimentos em trabalhos relacionados, faz-se necessário que a escola (como um todo) faça uso dessas tecnologias para promover não só a formação do conhecimento, mas também propiciar ao aluno experiências com trabalho em equipe e autonomia, de uma forma lúdica.

O principal intuito da presente pesquisa foi a análise da experiência de jovens ao interagir com um jogo digital para aprendizagem de Matemática. Para isso foi desenvolvida a versão digital do jogo matemático Cubra Doze, que foi aplicada em ambiente escolar. Os dados foram coletados por meio de observações de campo e questionários.

Os resultados confirmam o interesse e entusiasmo dos jovens na utilização de atividades lúdicas digitais atreladas a conteúdos matemáticos. Além de ter fícado evidente que o jogo despertou um grau considerável de engajamento nos alunos, é importante ressaltar as vantagens que o jogo digital traz em comparação a sua versão física: a possibilidade de feedback imediato, amenizando assim a necessidade constante de um educador, que nem sempre é viável dada a grande quantidade de alunos por turma; e a possibilidade de ter um material disponível e validado, e que pode ser facilmente modificado para incorporar novos aspectos motivadores, como foi o caso do temporizador em cada jogada. Os resultados obtidos confirmam que a abordagem de virtualização de jogos tradicionais tem grande potencial merece atenção de pesquisadores.

Como trabalhos futuros, seria interessante a aplicação do jogo em turmas de diferentes anos letivos, visando identificar os benefícios de acordo com cada nível escolar, comparando o engajamento, além de uma avaliação mais longitudinal, em que o jogo estivesse integrado ao planejamento didático do professor. 


\section{Referências}

Batista, E. J. S., Mioto, J., Bogarim, C. A. C., Lima, A., e Araujo, Q. (2017). As Aventuras de Calculino: jogo para ensino de raciocínio lógico.

Brom, C., Preuss, M., e Klement, D. (2011). Are educational computer micro-games engaging and effective for knowledge acquisition at high-schools? A quaseexperimental study.

da Silva, K. e Costa, M. (2017). JOGOS DIGITAIS NA ESCOLA: a utilização como objetos de aprendizagem no ensino da matemática.

da Silva Neto, S. R., Santos, H. R. M., de Souza, A. A., e dos Santos, W. O. (2013). Jogos Educacionais como Ferramenta de Auxílio em Sala de Aula.

de Oliveira, R. G. (2014). A aplicação do jogo Sudoku no ensino médio como ferramenta para auxiliar o discente a pensar e refletir.

de Santana, S. J. e dos Santos, W. O. (2018). Jogos Educativos no Ensino de Matemática: Qual a Melhor Abordagem?

dos Santos, W. O. (2018). EGV: A Methodology Proposal to Educational Games Virtualization.

dos Santos, W. O. e da Silva Junior, C. G. (2014). Uso de Jogos no ensino da Matemática: Uma análise entre os jogos tradicionais e os jogos digitais, baseada em pesquisa e mapeamento dos materiais encontrados na Web.

dos Santos, W. O., da S. Neto, S. R., e da Silva Junior, C. G. (2015). Processo de Virtualização de Jogos para Uso como Mecanismo de Apoio ao Processo de Ensino e Aprendizagem da Disciplina de Matemática.

Felicia, P. (2009). Digital games in schools: Handbook for teachers.

Kafai, Y. B. (1995). Minds in Play: Computer Game Design As A Context for Children's Learning.

Ribeiro Junior, O. A. (2018). Desenvolvimento do Raciocínio Lógico por Meio do Jogo de Sudoku: Um estudo no $1^{\circ}$ ano do Ensino Médio do IFTO - Campus Paraíso.

Rosa, M. (2004). Role Playing Game Eletrônico: uma tecnologia lúdica para aprender e ensinar Matemática. Pós-graduação em educação matemática.

Santos, W. O., Silva Neto, S. R., e Silva Junior, C. G. (2013). Uso de Games no ensino da Matemática. Uma proposta de virtualização dos jogos tradicionais, para uso como mecanismo de apoio ao processo de ensino e aprendizagem.

Savi, R., von Wangenheim, C. G., Ulbricht, V., e Vanzin, T. (2010). Proposta de um Modelo de Avaliação de Jogos Educacionais. 